Cadernos de Clio, Curitiba, v. 11, $\mathrm{n}^{\circ} .1,2020$

\title{
OLÍVIO/FELÍCIO: DE PORTUGAL À ÁSIA E DE VOLTA: UMA ANÁLISE DA REPRESENTAÇÃO DA NATUREZA EM LUSITÂNIA TRANSFORMADA (1607)
}

\section{OLÍVIO/FELÍCIO: FROM PORTUGAL TO ASIA AND BACK: AN ANALYSIS OF NATURE'S REPRESENTATION IN LUSITÂNIA TRANSFORMADA (1607)}

Fabio Wroblewski Filhol

Resumo: Este artigo objetiva analisar de que forma Fernão Álvares do Oriente, autor português do século XVI, caracteriza a natureza asiática em sua obra mais famosa, Lusitânia Transformada (1607). Em primeiro lugar, há uma breve descrição de aspectos biográficos do autor, assim como dos aspectos formais e literários de Lusitânia Transformada. O pensamento do geógrafo humanista francês Eric Dardel é utilizado, em seguida, como principal referencial teórico para a análise proposta, considerando suas contribuições acerca da subjetividade presente no espaço geográfico. Enfim, o artigo explora como o livro de Fernão Álvares pode ser interpretado como um manifesto contra as expansões marítimas que guiavam Portugal em sua época.

Palavras-Chave: Fernão Álvares do Oriente; Lusitânia Transformada; expansão marítima; Império Português.

Abstract: This article aims to analyze how Fernão Álvares do Oriente, a Portuguese author from the sixteenth century, describes Asian nature in his most famous work, Lusitânia Transformada (1607). In the first place, there is a brief description of biographical aspects of the author, as well as the formal and literary aspects of Lusitânia Transformada. The thought of the

\footnotetext{
${ }^{1}$ Discente da graduação em História pela Universidade Federal do Paraná (UFPR). E-mail para contato: fabtt2010@hotmail.com. Endereço para o Currículo Lattes: http://lattes.cnpq.br/6297433660847580.
} 
French humanist geographer Eric Dardel is used then as the main theoretical reference to the proposed analysis, considering his contributions concerning the subjectivity present in geographical space. At the end, the article explores how Fernão Álvares' book may be interpreted as a manifesto against the maritime expansions that guided Portugal at his time. Keywords: Fernão Álvares do Oriente; Lusitânia Transformada; Maritime expansion; Portuguese Empire.

Comme le voyageur qui navigue entre les îles de l'Archipel voit la buée lumineuse se lever vers le soir, et découvre peu à peu la ligne du rivage, je commence à apercevoir le profil de ma mort (YOURCENAR, 1951: 13).

\section{A singularidade de Fernão Álvares do Oriente}

O topos do locus amoenus está presente na literatura desde a Antiguidade, designando a criação de um lugar seguro fora do espaço e do tempo, essencialmente onírico e tranquilo, no qual os personagens podem encontrar um refúgio temporário, retornando, então, para a realidade renovados (MULINACCI, 1996). A presença desta geografia lírica é, simultaneamente, o que alinha Lusitânia Transformada (1607), de Fernão Álvares do Oriente, a outras obras produzidas no mesmo contexto e o que a singulariza, tendo em vista que o topos é utilizado em uma estratégia narrativa que subverte sua função tradicional. Assim, a obra é identificada ao pastoralismo, maneirismo ou bucolismo quinhentista português (FINAZZI-AGRÓ, 1978; MULINACCI, 1976), mas se destaca pela presença de elementos que situam a narrativa em um contexto histórico definido, subvertendo a liricidade própria ao locus amoenus. 
A contextualização do autor se faz essencial não apenas para que possamos entender a partir de onde e quando surge sua produção, mas também devido ao caráter autobiográfico que permeia a Lusitânia Transformada (AUGUSTO, 2013), característica comum em obras de caráter bucólico. Fernão Álvares, chamado do Oriente, nasceu provavelmente em Goa, por volta de 1530. Serviu à Coroa em diversas missões bélicas, sendo um dos poucos sobreviventes da batalha de Alcácer-Quibir (1578) e tomado prisioneiro. Seus dados biográficos são muitas vezes incertos. Estima-se que morreu nos primeiros anos do século XVII, considerando que a publicação de sua obra foi póstuma, como atestado pelo prólogo, escrito pelo livreiro Domingues Fernandes (MULINACCI, 1996; FINAZZI-AGRÓ, 1978).

A principal obra de Fernão Álvares do Oriente, Lusitânia Transformada, foi publicada em 1607, dirigida ao capitão-mor e governador de Ceuta, Dom Miguel de Menezes, com licença do Supremo Conselho da Santa Inquisição. Sua estrutura interna, assim como seu conteúdo, é fragmentada, o que impossibilita uma descrição ou resumo que a una em uma linha geral. Finazzi-Agró (1978: 79) argumenta que a obra mais parece uma justaposição de episódios que uma narrativa única. Para além dos episódios narrados em prosa há também segmentos em verso. Forma, portanto, uma estrutura em geral dividida em três livros, subdivididos em prosas separadas por momentos poéticos. Formalmente, o livro alinha-se a uma tradição bucólica, pastoril, sobretudo pela presença de alusões à natureza e pelos problemas de ordem sentimental. 
Em relação ao conteúdo, as narrativas convergem na figura de Felício, chamado de Olívio quando no Oriente, que decide narrar sua jornada de desventuras amorosas e o epifânico retorno a Portugal, o locus amoenus da obra. Olívio nasceu em Goa e teve a formação marcada tanto pelo estudo das letras quanto das artes bélicas. Episódios de sua vida são permeados pela narração de suas viagens pelo "Oriente”, um grande espaço poucas vezes especificado. Cumpre notar desde já que a ambientação é um aspecto fundamental a ser tratado, essencial para a caracterização das narrativas bucólicas, e que será explorado com mais profundidade posteriormente.

Por agora devemos nos atentar à singularidade da obra: seu caráter histórico explícito. Como já apresentado, Lusitânia transformada é uma obra pastoril, categoria recebida sobretudo pelo uso do topos do locus amoenus e da onipresente lírica natural. No entanto, esta poética encobre uma preocupação política do autor com o seu tempo. Fernão Álvares utiliza os recursos bucólicos tradicionais para apresentar suas críticas em relação aos rumos de Portugal, desenvolvendo uma dialética entre ficção e realidade que aprofunda a forma literária escolhida (FINAZZI-AGRÓ, 1978: 80-81). O espaço de refúgio do protagonista não pertence a uma dimensão fora do espaço e do tempo, pelo contrário, é geograficamente determinado, é Portugal. Este aspecto contrasta com outras obras do cânone pastoril, como aquelas produzidas por Francisco Rodrigues Lobo no mesmo momento (CRISTÓFANO, 2010). Outra subversão da tradição levada a cabo pelo autor, como assevera Mulinacci (1976: 7), é a posição 
do locus amoenus, que deixa de ser um ponto de partida de um indivíduo renovado para ser o ponto de chegada, o local de um exílio voluntário do mundo tal como ele se apresentava naquele momento. $\mathrm{O}$ espaço de Felício, que muda de nome como forma de indicar que é um homem novo e agora se sente feliz, é uma alternativa ideal. O percurso, externo e interno, de Olívio/Felício é uma característica comum das narrativas bucólicas, como apresenta Augusto (2013: 199). Contudo, se em outras obras o destino final é a impossibilidade da felicidade sem amor, Fernão Álvares do Oriente inova ao apresentar uma substituição do amor humano pelo amor divino, e sua consequente realização em um espaço pastoril e religioso.

A identificação de Portugal como o locus amoenus na obra indica uma crítica do autor à situação enfrentada pelos lusitanos à época. Mulinacci (1976: 8) argumenta que o que há são duas formas antitéticas de pensar os destinos históricos de Portugal, de um lado a ambição expansionista que levou a Coroa a estender seus domínios até a Ásia; do outro, a concepção "ruralizada" de Fernão Álvares, que se opõe às expansões, creditando estas à cobiça desmedida que estava levando o reino à miséria. Nesse sentido, a Lusitânia Transformada se insere na corrente maneirista, por apresentar o mundo como um lugar de infelicidades do qual é preciso escapar.

\section{Percorrendo os caminhos de uma geografia de sonho}

Para Eric Dardel, geógrafo francês humanista, os exploradores do século XVI eram “poetas do espaço” (DARDEL, 2013: 149). Em sua obra 
publicada originalmente em 1952, L'homme et la Terre: Nature de la réalité géographique, Dardel explora filosoficamente a relação entre os seres humanos e a realidade geográfica que nos cerca. $\mathrm{O}$ autor traça uma breve história da geografia, desde a geograficidade essencial da condição humana, ou seja, uma atitude de ser que está em uma batalha constante com o espaço, até a geografia científica que se forma no século XIX (DARDEL, 2013). O geógrafo francês argumenta que é a partir da primeira modernidade que a atitude frente à Terra começa a mudar. Se até então o humano era movido pela vontade de explorar, a partir deste momento a racionalidade começa a se tornar um instrumento de compreensão. Os humanos, então, passam a empregar critérios "objetivos" de forma a classificar, medir e, sobretudo, explicar o espaço geográfico. Nesse processo a relação fundamental da existência humana com o seu redor é enfraquecida, uma condição que Dardel quer combater, defendendo uma relação para além do real com nosso planeta.

Um argumento essencial de Dardel é que o espaço terrestre é sempre "para o homem" - ou seja, o autor parte de uma perspectiva antropocêntrica segundo a qual a realidade material é sempre percebida subjetivamente pelos seres humanos, que a classificam de acordo com seus próprios critérios (DARDEL, 2013: 64-65). Ademais, ainda de acordo com esta visão, o território está sempre impregnado pela existência própria daqueles que o percebem, não há uma neutralidade, tendo em vista que a mediação entre o material e o humano é feita a partir das experiências subjetivas, como explica Dardel: 
Sin lugar a dudas, la realidad tan concreta y tan cercana de la Tierra no se aprehende más que a través de una interpretación de conjunto que es una forma de acercarse al Ser. El 'color' bajo el que nos aparece la realidad geográfica depende de la preocupación y del interés dominantes que nos lleven al encuentro de existencias particulares (DARDEL, 2013: 93).

Seguindo este princípio, a linguagem do geógrafo deve se aproximar da linguagem do poeta, pois a realidade física carrega consigo camadas de significados culturais que em muito ultrapassam sua aparente neutralidade. Os fenômenos naturais são adjetivados subjetivamente de forma que "[...] el lenguaje geográfico transporta las sorpresas, las privaciones, los sufrimientos o las alegrías que se atribuyen a las regiones" (DARDEL, 2013: 97-98). É neste ponto que podemos conjugar a visão de Dardel com a obra de Fernão Álvares do Oriente. As descrições do escritor quinhentista podem ser compreendidas como fontes ricas para se estudar a perspectiva portuguesa da Ásia, ou mais especificamente a perspectiva do autor de Lusitânia Transformada, partindo de suas abundantes narrações acerca dos territórios do "Oriente", decorrentes do fato de que a natureza é um tema particularmente importante para a tradição bucólica da qual Fernão Álvares (formalmente) adota.

Convém apresentar o conceito da paisagem e discutir como ele pode ser trabalhado nas obras de arte. Mendes (2015: 253) argumenta que o conceito de paisagem faz parte da cultura geral, sendo objeto de estudo da geografia. Uma paisagem é uma visualização do espaço, sobre a qual inferimos qualidades subjetivas, que refletem projeções estéticas sociais 
(MENDES, 2015: 253). Também Dardel apresenta sua perspectiva sobre o tema, para ele "más que una yuxtaposición de detalles pintorescos, el paisaje es un conjunto: una convergencia, un momento vivido. Un vínculo interno, 'una impresión' une todos sus elementos" (DARDEL, 2013: 90). Em suma, o que é ressaltado é a importância da subjetividade na descrição do espaço físico. Tendo isto em mente, as descrições de Olívio são a expressão do pensamento do autor que, fazendo uso das convenções da ficção pastoril, argumenta em favor de um projeto para o futuro de sua pátria, como ficará mais claro adiante.

O Oriente de Olívio é marcado pelo exótico, rico e diferente. A natureza é cheia de vida e fértil de promessas. As descrições quase naturalistas da paisagem que cerca o personagem principal podem ser exploradas em seus inúmeros significados (intencionais ou não). O trecho seguinte exemplifica as narrações contemplativas que estão presentes em toda a obra:

Aqui me assentey entre aruores fructiferos sobre flores olorosas, \& discorrendo pensamentos varios, me ajadaua do silencio da escura noite, \& da luz amiga da fermosa Lûa (que ja então alumiaua o mundo) para penetrar alguns segredos da natureza, que na variedade das cousas, que as terras Orientais produzem, se mostra alli mais poderosa (ÁLVARES, 1607: $114)^{2}$

2 “Aqui me assentei entre árvores frutíferas sobre flores olorosas, e discorrendo pensamentos vários, me ajudava do silêncio da escura noite, e da luz amiga da formosa Lua (que já então alumiava o mundo) para penetrar alguns segredos que na variedade das coisas, que as terras orientais produzem, se mostra ali mais poderosa." 
A natureza oriental é poderosa, os frutos são abundantes e as flores cheirosas. Olívio é Portugal descobrindo os segredos do outro lado do mundo, e o choque com a alteridade é propício para se descobrir alguns "segredos da natureza". O ambiente, que faz também as vezes de personagem, é descrito em detalhes. Olívio registra em sua narrativa espécimes específicos de plantas que o seduzem e/ou espantam. A árvore triste, tão comum naquelas terras, mas ao mesmo tempo tão peculiar para o viajante europeu, é um exemplo:

Noutra planta (de que n'aquelle lugar auia grande copia) a qual por delicado antifrasi, chamão os naturais aruore triste [...] A flagrancia do cheiro, que suas flores respirauão, feridas d'hum brando vento, que as sacudia, era para tornar â vida quem quasi d'ella estiuera priuado (ÁLVARES, 1607: $114-114 \mathrm{~V}) .^{3}$

No entanto, as novas terras descobertas são, além da promessa do futuro, um perigo latente. A imagem do fruto no livro de Fernão Álvares é particularmente esclarecedora nesse caso. Ainda contemplando a natureza ao seu redor, Olívio se depara com uma árvore frutífera: "Via entre outras plâtas a palma fructifera, que penetrando as nuuens aleuanta ao ceo o seu

\footnotetext{
3 "Noutra planta (de que naquele lugar havia grande cópia) a qual por delicado antifrasi chamam os naturais árvore triste [...] A fragrância do cheiro, que suas flores respirava, feridas de um brando vento, que as sacudia, era para tornar à vida quem quase dela estivera privado.”
} 
pezado fruto, que cheo, quando tenro, d'agoa suauissima, parece na doçura compitir com o celestial Ambrosia" (ÁLVARES, 1607: 114). ${ }^{4}$

Logo em seguida outro vegetal é descrito, mas ao invés da doçura e da beleza o que se observa é o possível sofrimento:

[...] entre as plantas que no mato via, hûas que da terra pouco mais, q hû couado se aleuantão, com hum fruto tam prejudicial, q em pòs desfeito, priua a quem em qualquer manjar os toma por espaço largo, do vso de todos os sentidos, com effeitos taõ miseraueis, que tiuera por melhor sorte outro tanto espaço carecer de vida (ÁLVARES, 1607: 114V-115). ${ }^{5}$

É notável como o autor faz uso de imagens naturais para expressar suas opiniões acerca das explorações portuguesas. Como supracitado, de acordo com Dardel, a visão acerca do ambiente é sempre marcada pela subjetividade, de forma que a linguagem geográfica se aproxima daquela do poeta. Mais livre, contudo, é o poeta que, fazendo uso da licença que lhe é própria, pode adicionar conscientemente camadas de significados. $\mathrm{O}$ fruto é o resultado que, embora aparentemente doce e celestial, pode causar também muita dor de forma que a morte seria melhor.

\footnotetext{
4 "Via entre outras plantas a palma frutífera, que penetrando as nuvens alevanta ao céu o seu pesado fruto, que cheio, quando tenro, d'água suavíssima, parece na doçura competir com o celestial Ambrosia."

5 “[...] entre as plantas que no mato via, umas que da terra pouco mais, que um côvado se levantam, com um fruto tão prejudicial, que em pós desfeito, priva a quem em qualquer manjar os toma por espaço largo, do uso de todos os sentidos, com efeitos tão miseráveis, que tivera por melhor sorte outro tanto espaço carecer de vida."
} 
Considerando que estamos tratando de um autor português do século XVI, outro elemento natural é de suma importância: o mar. Dardel credita ao oceano um papel importante; se para o autor a natureza é uma linguagem que temos de decifrar, as águas sussurram constantemente:

En la orilla está el hombre: desde alli da rienda suelta a sus sueños y a sus aventuras; desde alli parte como los focenses y los normandos hacia nuevas orillas; desde alli llevará la guerra o el comercio a otros pueblos. Muchos son aquellos que han respondido a la llamada de la mar o que han hecho de ella el medio de comunicarse (DARDEL, 2013: 80).

Na obra de Fernão Álvares, o personagem Olívio viaja por todo o Oriente em embarcações, naturalmente, assim como os inúmeros exploradores, comerciantes e missionários portugueses o fizeram historicamente. O mar é um elemento separador, mas estava então sendo dominado com o desenvolvimento de novas técnicas e tecnologias (THOMAZ, 1994: 6). Por isso o percurso marítimo revestiu-se de fundamental importância na cultura portuguesa. A representação presente em Lusitânia Transformada é eloquente. Olívio vive apuros quando está a bordo em direção à "Ilha formosa", uma súbita tempestade se forma e castiga a embarcação por três dias:

Pronosticando estauão semelhãtes infortunios os expertos mareantes, quando cubrindose os ceos subitamente d'hûa expessa nuuê, que nos priuou da luz do dia, despidio de si tam ardêtes rayos, que parecia a ruynar de todo a machina celeste [...] Os ventos assobiando, antes bramindo a leuantauam as ondas, que com impeto desmedido constrastauam a nao, que ja 
quasi se rêdia combatida da força de taõ poderosos inimigos (ÁLVARES, 1607: 154). ${ }^{6}$

As ondas são "inimigas" e a tempestade é capaz de afetar a "máquina celeste". No entanto, na manhã do terceiro dia o céu volta a clarear e o mar já não é mais o mesmo:

O mar não parecia ser aquelle, q pouco antes viramos, antes ja outro nos daua licença, que por sima de suas ondas muy humildes [...], desembarcamos na praya da ilha, que conhecida no mundo por fermosa, tomou o nome: Polla terra estendemos desejosos de satisfazer no terreno fresco, \& amigo da propria natureza, o dispêdio, q causou o mar seu aduersario (ÁLVARES, 1607: 163V). ${ }^{7}$

A transformação permite que os tripulantes desembarquem na Ilha, onde será contada a história da Princesa Dinabela e do Príncipe Arima, que, como aponta Augusto (2013: 204), é um conto de caráter moralizante. A máquina celestial volta a rodar indicando enfim um caminho para $\mathrm{o}$ protagonista, pois depois de mais uma decepção amorosa, Olívio decide

\footnotetext{
6 "Prognosticando estavam semelhantes infortúnios os expertos mareantes, quando cobrindo-se os céus subitamente de uma espessa nuvem, que nos privou da luz do dia, despediu de si tão ardentes raios, que parecia arruinar de todo a máquina celeste [...] Os ventos assobiando, antes bramindo a levantavam as ondas, que com ímpeto desmedido contrastavam a nau, que já quase se rendia combatida da força de tão poderosos inimigos."

7 “O mar não parecia ser aquele que pouco antes vimos, antes já outro que nos dava licença, que por cima de suas ondas muito humildes [...], desembarcamos na praia da ilha, que conhecida no mundo por formosa, tomou o nome: Pela terra estendemos desejosos de satisfazer no terreno fresco, e amigo da própria natureza, o dispêndio que causou o mar seu adversário."
} 
regressar a Portugal, onde encontrará seu locus amoenus e se tornará Felício. Ocorre, então, a metamorfose dos "passados infortúnios" narrados, representando o amor terreno, para a vida no "sítio deleitoso", que, por sua vez, é o amor divino.

\section{Portugal deve voltar}

Um império é toda e cada pessoa que o compõe, da mesma forma que toda e cada pessoa representa a Coroa. Olívio/Felício representa Portugal na obra de Fernão Álvares do Oriente, um povo que passeia pela Ásia se aventurando em amores terrenos, esquecendo-se do que é realmente importante. Um amor estrangeiro, marcado pelo exotismo que fascina, como um farol que atrai os navegantes, mas também é perigoso pois pode levar aqueles que o perseguem à ruína. Fernão Álvares caracteriza em seu protagonista um povo que deve voltar a si mesmo para poder, finalmente, encontrar a paz.

Fernão Álvares adota os procedimentos de uma determinada tradição literária apenas como um véu que cobre seu verdadeiro pensamento. A subversão realizada de situar o espaço, por definição ideal, é um indício de que a bucólica metamorfose aparente é o disfarce de uma esperança profunda.

Segundo Mulinacci (1996: 8), Fernão Álvares lança anátemas contra a aventura ultramarina portuguesa, creditando a ela a miséria na qual o país se encontrava. O autor também argumenta que a Lusitânia Transformada é a apresentação de um novo modo de pensar o destino de Portugal 
(MULINACCI, 1996: 8). Este povo que foi pioneiro no processo das expansões marítimas, precedendo outras potências maiores de seu tempo, estava então perdido. O escritor lusitano seiscentista tenta com sua literatura segurar um espelho frente a um império decadente, um império que havia tentado agarrar o mundo com um braço na América e outro na Índia, esticando os dedos até o Japão e a China, mas que em última instância se mostrava incapaz de manter o projeto expansionista que guiava inúmeros exploradores.

A narrativa de Lusitânia Transformada convidava seus coetâneos a refletir sobre seu próprio tempo, e nesse sentido a paisagem representada era loquaz. Dardel (2013: 94) explica que:

Hay, en el paisaje, un rostro, una mirada, un oído, como una espera o un recuerdo. Cualquier espacialización geográfica es concreta y actualiza al hombre en su existencia, porque, en ella, el hombre se sobrepasa y escapa y conlleva de esta forma una temporalización, una narración, un acontecimiento.

A perspectiva que o presente trabalho quis propor é a de que o personagem Olívio/Felício é a representação do povo português, e, por conseguinte, de Portugal, e que para Fernão Álvares sua pátria deveria renunciar aos amores terrenos da Ásia para encontrar em si mesma o amor divino.

\section{Referências}


AUGUSTO, Sara. Visão e Viagem do Oriente na Lusitânia Transformada. Máthesis, n. 22, p. 197-208, 2013.

CRISTÓFANO, Sirlene. Literatura, Natureza e Espaço: Representações do Amor na Novela Pastoril, de Francisco Rodrigues Lobo. Literatura em debate (URI), v. 4, p. 76-93, 2010.

DARDEL, Eric. El hombre y la tierra: Naturaleza de la realidad geográfica. Madrid: Biblioteca Nueva, 2013.

FINAZZI-AGRÓ, Ettore. Novelística portuguesa do século XVI. Lisboa: Instituto de Cultura Portuguesa, 1978.

MADEIRA DAVIM, David Emanuel. O homem e a terra: natureza da realidade geográfica. (Eric Dardel, 2011). Revista da Abordagem Gestáltica: Phenomenological Studies, v. XXII, n. 2, p. 249-252, jul./dez. 2016.

MENDES, Rui Paes. A Paisagem como elemento de apropriação artística. Diacritica, v. 29, n. 2, p. 251-267, 2015.

MULINACCI, Roberto. Loci amoeni e ilhas afortunadas de Fernão Álvares do Oriente: Tradição e inovação na Lusitânia Transformada de Fernão Álvares do Oriente. Rassegna Iberistica, n. 58, p. 3-17, 1996.

THOMAZ, Luís Filipe. Expansão portuguesa e expansão europeia: reflexões em torno da génese dos descobrimentos. In: . De Ceuta a Timor. 2. ed. Lisboa: Difel, 1994.

QUINT, Anne-Marie. Pastores no mar: o espaço marítimo nos romances pastoris de Fernão Álvares do Oriente e Francisco Rodrigues Lobo. Revista de Letras, v. 39, p. 25-36, 1999.

Recebido em: 24/02/2021

Aceito em: 21/04/2021 